\title{
Axial and Radial Material Flow Analysis in Infeed Rotary Swaging of Tubes
}

\author{
Yang Liu ${ }^{1, *}$, Marius Herrmann ${ }^{1}$, Christian Schenck $^{1,2}$, and Bernd Kuhfuss ${ }^{1,2}$
}

${ }^{1}$ bime, Bremen Institute of Mechanical Engineering, University of Bremen, 28359, Bremen, Germany

${ }^{2}$ MAPEX Center for Materials and Processing

\begin{abstract}
In rotary swaging - an incremental cold forming production technique to reduce the diameter of axisymmetric parts - the material flow can be assumed to be predominantly axial and radial. The actual ratio of this axial and radial flow influences the mechanical properties and especially in tube forming the final geometry. It is known that during mandrel free infeed rotary swaging of tubes the wall thickness changes. The change is depending on the process parameters like incremental and cumulated strain. Hence, the ratio of axial and radial material flow changes. Consequently, the analysis of the wall thickness of rotary swaged tubes enables fundamental insight how to control the material flow direction. In this study, the infeed rotary swaging process of steel tubes with different wall thicknesses from $3 \mathrm{~mm}$ to $7 \mathrm{~mm}$ and rods were investigated with FEM under two feeding velocities. The axial and radial material flow and the resulting geometry were studied by the relative wall thickness. It could be seen that the relative wall thickness was affected by the feeding velocity as well as the initial wall thickness. The findings of the simulation were validated by rotary swaging experiments.
\end{abstract}

Keywords: Metal forming, Cold forming, Modeling

\begin{tabular}{|c|c|c|}
\hline \multicolumn{3}{|c|}{ Nomenclature } \\
\hline $\mathrm{d}_{0}$ & initial diameter & $\mathrm{mm}$ \\
\hline $\mathrm{d}_{1}$ & final diameter & $\mathrm{mm}$ \\
\hline$f_{\text {st }}$ & stroke frequency & $\mathrm{Hz}$ \\
\hline $\mathrm{h}_{\mathrm{T}}$ & stroke height & $\mathrm{mm}$ \\
\hline $1_{0}$ & initial length & $\mathrm{mm}$ \\
\hline$l_{1}$ & final length & $\mathrm{mm}$ \\
\hline $\operatorname{lh}$ & drilling length & $\mathrm{mm}$ \\
\hline $\mathrm{R}_{\mathrm{n}}$ & radial neutral boundary & - \\
\hline $\mathrm{R}_{\mathrm{nr}}$ & position of $R_{n}$ & $\mathrm{~mm}$ \\
\hline $\mathrm{R}_{\mathrm{np}}$ & radial relative position of $R_{n r}$ & $\%$ \\
\hline So & initial wall thickness & $\mathrm{mm}$ \\
\hline $\mathrm{s}_{1}$ & final wall thickness & $\mathrm{mm}$ \\
\hline S1-fem & final wall thickness of FE model & $\mathrm{mm}$ \\
\hline S1-exp & final wall thickness of experiment & $\mathrm{mm}$ \\
\hline $\mathrm{Sn}$ & wall thickness that enables $\Delta s_{p}=0$ & $\mathrm{~mm}$ \\
\hline $\mathrm{vf}$ & feeding velocity & $\mathrm{mm} / \mathrm{min}$ \\
\hline yo & original mesh height & $\mathrm{mm}$ \\
\hline $\mathrm{y}_{1}$ & final mesh height & $\mathrm{mm}$ \\
\hline $\mathrm{z} 0$ & original mesh length & $\mathrm{mm}$ \\
\hline $\mathrm{z} 1$ & final mesh length & $\mathrm{mm}$ \\
\hline I & reduction zone & - \\
\hline II & calibration zone & - \\
\hline III & exit zone & - \\
\hline$\alpha$ & die angle & $\circ$ \\
\hline
\end{tabular}

\begin{tabular}{lll}
$\Delta \mathrm{sp}_{\mathrm{p}}$ & change of wall thickness & $\%$ \\
$\Delta \mathrm{y}_{\mathrm{p}}$ & change of mesh height & $\%$ \\
$\Delta \mathrm{z}_{\mathrm{p}}$ & change of mesh length & $\%$ \\
$\delta$ & relative error of FE model & $\%$ \\
$\mu$ & friction coefficient & - \\
\hline
\end{tabular}

\section{Introduction}

Rotary swaging is an incremental cold forging process. Usually it is used for reducing the cross section of rods and tubular workpieces, or for achieving certain wall thicknesses of tubes [1]. This technology can improve the material strength as well as the surface condition with reduced roughness values. In addition, this process can produce advantageous inner profiles for tubes [3]. Nowadays, rotary swaging is widely used in automobile and textile industry [4]. The main part of a rotary swaging machine is the swaging head, wherein two or more dies are concentrically arranged. During the process, the dies rotate with the driving shaft. Simultaneously, the dies strike repeatedly towards the workpiece in the center. The forming is achieved either by axially feeding of the workpiece into the swaging 
head (infeed rotary swaging) or by radially feeding of the dies (plunge rotary swaging).

The principle of mandrel free infeed rotary swaging is shown in Figure 1. According to the geometry, the die is distinguished into three main zones: reduction zone (I), calibration zone (II) and exit zone (III). During the process, the plastic deformation of the workpiece appears mainly in the reduction zone, which features the die angle $\alpha$. The main material flow is initiated in this zone. In the calibration zone and exit zone the geometry of the workpiece is predominantly maintained. The main parameters of the process are feeding velocity $\left(\mathrm{v}_{\mathrm{f}}\right)$, striking frequency $\left(\mathrm{f}_{\mathrm{st}}\right)$ and stroke height $\left(\mathrm{h}_{\mathrm{T}}\right)$. The geometry of the tubes is given by the initial diameter $\left(\mathrm{d}_{0}\right)$ and the initial wall thickness $\left(\mathrm{s}_{0}\right)$. After the deformation a final diameter $\left(d_{1}\right)$ and final wall thickness $\left(s_{1}\right)$ are achieved. When the calibration zone is fully filled during the process, a quasi-constant condition is established. Thus, the same amount of material is deformed with the same conditions with every further stroke. In this situation, a stable phase is assumed [5].

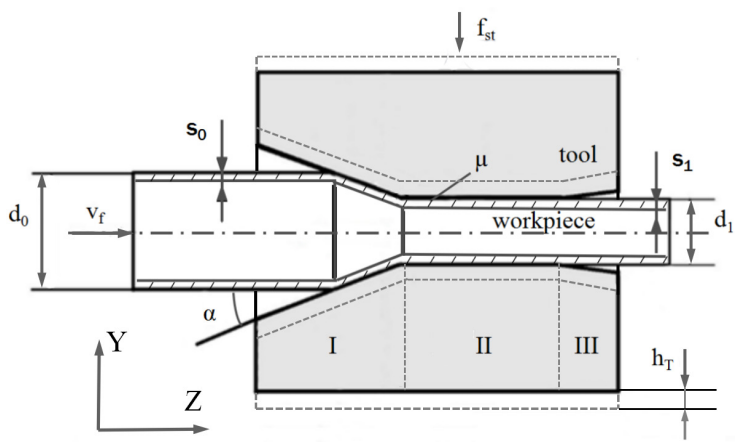

Fig. 1. Principle of mandrel free tube infeed rotary swaging.

In former research, rotary swaging has been widely investigated by Finite Element Method (FEM) and experiments. Rong et al. [6] studied the radial material flow in pure magnesium rods with simulations. They found that the radial strain distribution was not notably affected by different values of $v_{f}$. Moumi et al. [7] studied the material flow by $2 \mathrm{D}$ axisymmetric simulations and the means of the axial neutral plain -the zone where the actual axial velocity equals Zero. They identified that the neutral plane was changing in shape and position during one stroke. Gan et al. [8] and Abdulstaar et al. [9] investigated the microstructures and tensile properties of commercial pure magnesium and pure aluminum in rotary swaging experiments. They found that both materials were gradually refined and the tensile yield strength was increased due to material flow. Ishkina et al. realized asymmetric strokes and used flat dies to change the radial material flow. They produced hexagonal wires and found that the shear strain distribution could be affected by these measures. In consequence, the formability of AISI304 in subsequent cold extrusion operations was improved $[2,10]$.

According to former research [11], tubes with $\mathrm{d}_{0}=8 \mathrm{~mm}$ and $\mathrm{s}_{0}=0.4 \mathrm{~mm}$ developed a thicker $\mathrm{s}_{1}$ after forming. For tubes with $\mathrm{s}_{0}$ higher than a half of $\mathrm{d}_{1}, \mathrm{~s}_{1}$ must become definitely smaller than $\mathrm{s}_{0}$. Hence, the radial material flow must change significantly depending on the initial wall thickness $\mathrm{s}_{0}$. Due to the constancy of material volume, when the cross section of the workpiece is reduced in the process, the material flows both in axial and radial directions. Additionally, the reducing of the cross section of the workpiece is finished with many increments. That makes the material flow complex, because the same part of the workpiece experiences different load conditions in different zones of the dies. Beneath the final geometry of the product the material flow also changes mechanical properties. Consequently, a profound knowledge of the material and its dependency on processing parameters is needed for improved controllability and further optimization.

In this paper, mandrel free infeed rotary swaging process of steel alloy (1.0308) tubes was studied with varying wall thickness and feeding velocity values by simulations and experiments. The data from simulation and experiment were represented as "fem" and "exp" for short.

\section{Methods}

In FE model, the process was realized in the general finite element software ABAQUS (version 6.13). A 2D axisymmetric explicit model was used based on [12] (Figure 2) with following assumptions: isotropic material; negligible thermal influence; constant friction condition between the contact pair. Coulomb friction was assumed despite the expected high normal forces as it was used and discussed in former literature [6, 7, 12 and 13]. The processing parameters in this FE model are shown in Table 1.

Table 1 Parameters of the experimental settings.

\begin{tabular}{|c|c|c|}
\hline Name & Value & Unit \\
\hline $\mathrm{d}_{0}$ & 20 & $\mathrm{~mm}$ \\
\hline $\mathrm{d}_{1}$ & 15 & $\mathrm{~mm}$ \\
\hline $\mathrm{f}_{\mathrm{st}}$ & 37.5 & $\mathrm{~Hz}$ \\
\hline $\mathrm{h}_{\mathrm{T}}$ & 1 & $\mathrm{~mm}$ \\
\hline $\mathrm{V} f 500$ & 500 & $\mathrm{~mm} / \mathrm{min}$ \\
\hline $\mathrm{V}_{\mathrm{f} 2000}$ & 2000 & $\mathrm{~mm} / \mathrm{min}$ \\
\hline
\end{tabular}

In the model, the material was steel alloy (1.0308) whose plastic properties were from literature [15], the values of $\mathrm{s}_{0}$ were $3,4,5,6,6.5$ and $7 \mathrm{~mm}$. A square shaped CAX4RT mesh was used on the workpiece. The 


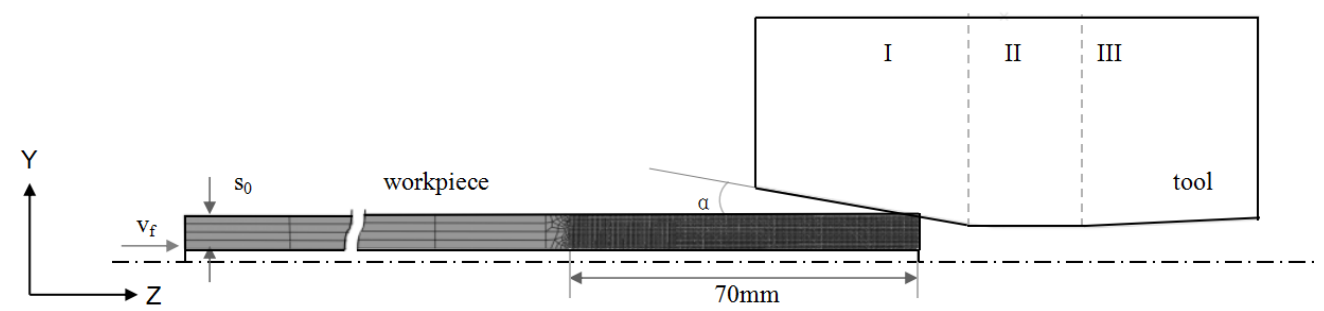

Fig. 2. FE model in ABAQUS 6.14, $\mathrm{s}_{0}=7 \mathrm{~mm}[12]$.

length of the workpiece with fine mesh was $70 \mathrm{~mm}$. This section that was involved in the deformation was meshed according to the initial wall thicknesses and radius. Remeshing was disabled. In this FE model, for thicker tubes with $\mathrm{s}_{0}$ higher than $5 \mathrm{~mm}$ more radial meshes were used as a common measure to avoid hourglass phenomenon [14]. Consequently, different mesh sizes were deployed. The length for each square was: $\mathrm{s}_{0} / 20$ for $3 \mathrm{~mm} \leq \mathrm{s}_{0} \leq 5 \mathrm{~mm}, \mathrm{~s}_{0} / 30$ for $6 \mathrm{~mm} \leq \mathrm{s}_{0} \leq 7 \mathrm{~mm}, \mathrm{~s}_{0} / 40$ for the rod [12]. According to literature the friction coefficient value of lubricated contact pair steel - steel is around 0.1 [16], so $\mu=0.1$ was used in this study. After the simulations were finished, the values of $s_{1 \text {-fem }}$ were measured at a point $35 \mathrm{~mm}$ from the end of undeformed material (A-A section in Figure 3), where the material was supposed to have experienced the whole deformation process after the stable phase was established.

In a detailed view, the shape change of mesh elements in axial and radial directions was analyzed as a measure of axial and radial deformation at A-A section. In Figure 3 the shape change of a mesh at the outer surface is illustrated. In this study, the shape changes of meshes from the outer surface to the inner surface were investigated.

As different mesh sizes used in the FE model, the changes of mesh shape in axial and radial direction were normalized by the initial dimensions:

$$
\begin{aligned}
& \Delta z_{p}=100 \% *\left(z_{1}-z_{0}\right) / z_{0} \\
& \Delta y_{p}=100 \% *\left(y_{1}-y_{0}\right) / y_{0}
\end{aligned}
$$

$\Delta z_{p}$ is the axial deformation, due to the features of rotary swaging, the workpiece should always be elongated, so the values of $\Delta z_{p}$ should always be positive. But according to former research the radial deformation for the meshes could be stretched or compressed, which means that the values of $\Delta y_{p}$ could be either positive or negative. It is supposed there might be an area where the value of $\Delta y_{p}$ is zero, which could be named as radial neutral boundary $\left(R_{n}\right)$ whose location could be marked as $\mathrm{R}_{\mathrm{nr}}$. The radial relative position according to $\mathrm{s}_{1}$ could be calculated as $R_{n p}$ as equation (3), which represents the radial ratio of $R_{n p}$ from the outer surface.

$$
R_{n p}=100 \% *\left(d_{1} / 2-R_{n r}\right) / s_{1}
$$

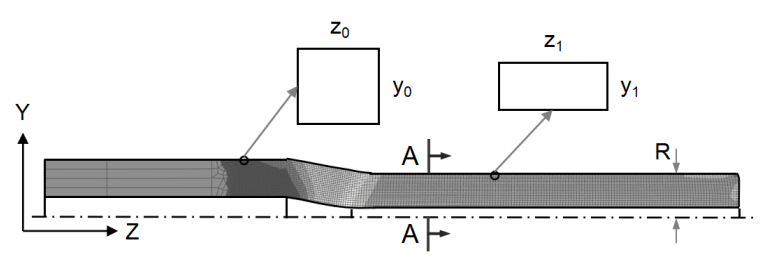

Fig. 3. Shapes of mesh before and after deformation (A-A section for measuring $\mathrm{S}_{1-\mathrm{fem}}$ ).

In the experiments, the tubes were manufactured from rods $\left(\mathrm{d}_{0}=20 \mathrm{~mm}\right.$ and $\left.\mathrm{l}_{0}=300 \mathrm{~mm}\right)$ by drilling to ensure equal starting conditions (Figure. 4). The length of drilling was $1_{h}=80 \mathrm{~mm}$. For each $\mathrm{s}_{0}$ three workpieces were prepared. Conventional swaging dies with tungsten carbide layer in the reduction zone were used [5], the contact pair was lubricated with oil (Condocut KNR 22). During the process the workpieces were fed into the center of the dies with a length of $70 \mathrm{~mm}$. Then they were pulled back. After the process, the geometry of the workpiece was changed as shown in Figure. 4.
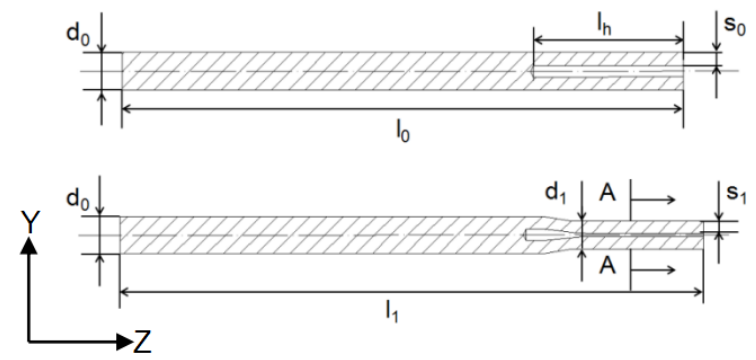

Fig. 4. Section view of the workpiece before and after the process, $\mathrm{s}_{0}=7 \mathrm{~mm}$. (A-A section for measuring $\mathrm{s}_{1-\exp }$ ).

After the experiments the values of $\mathrm{s}_{1 \text {-exp }}$ were measured at A-A section. The physical probes were measured by preparing metallographic specimens. A laser microscope was used to take five times enlarged photos of the cross sections. Based on the micrographs the values of $s_{1}$ were measured eight times for each of the three samples and the average value and variance were calculated. For the 
validation of the FE model, the values of relative error were calculated by the differences between the $\mathrm{s} 1$ values from simulation and experiment divided by the value from experiment (equation (4)).

$$
\delta=100 \% *\left(\mathrm{~s}_{1-\text { fem }}-\mathrm{s}_{1-\exp }\right) / \mathrm{s}_{1-\exp }
$$

The percentage of the wall thickness development $\left(\Delta s_{p}\right)$ was calculated by (equations $\left.(5)\right)$.

$$
\Delta s_{p}=100 \% *\left(s_{1}-s_{0}\right) / s_{0}
$$

\section{Results and discussion}

No matter which $\mathrm{s}_{0}$ was used, the length of the workpiece increased. So, the axial material flow is discussed firstly. The resulting values in axial direction $\Delta \mathrm{z}_{\mathrm{p}}$ for $\mathrm{v}_{\mathrm{f} 500}$ are shown along the radius (Y-axis) in Figure 5. These values of $\Delta z_{p}$ for both rod and tubes could be treated as constant values regardless of their locations in radial direction. Thus, the axial material flow is homogeneous. The mean values of $\Delta z_{p}$ are shown in Figure 6. $\Delta z_{p}$ increases almost linearly with higher value of $\mathrm{s}_{0}$; the influence of the feeding velocity $\mathrm{v}_{\mathrm{f}}$ is low and vanishes with higher $\mathrm{s}_{0}$. The reason for increasing $\Delta \mathrm{z}_{\mathrm{p}}$ along with $\mathrm{s}_{0}$ could be the increasing radial resistance due to more material to be deformed.

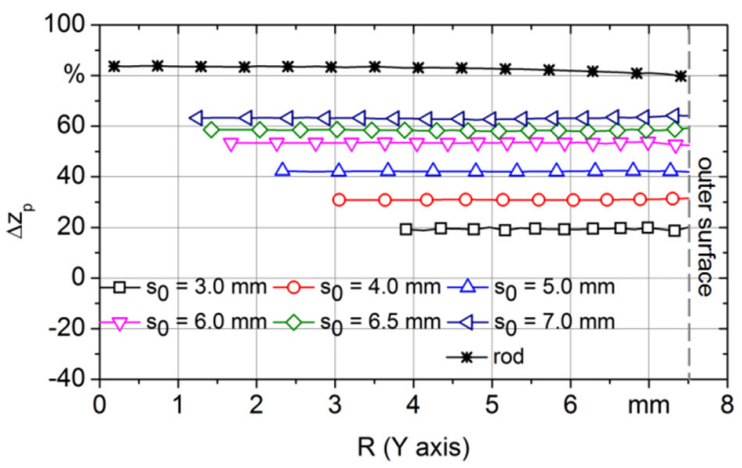

Fig. 5. Axial elongation $\Delta z_{p}$ of meshes for different wall thicknesses of tubes and rod for the feeding velocity $\mathrm{v}_{\mathrm{f} 500}$ at the position $\mathrm{A}-\mathrm{A}$.

With the same value of $\mathrm{s}_{0}$, higher $\mathrm{v}_{\mathrm{f}}$ led to an earlier contact between the dies and the workpiece during each stroke. Also, the contact length in the reduction zone was shorter and its center was shifted to the undeformed part; in the same time, due to an earlier contact the distance between the calibration zone and the deformed workpiece was longer, thus the friction resistance worked later compared to the situation with lower $v_{f}$. Due to this reasons, the material flow towards axial direction was easier for higher $\mathrm{v}_{\mathrm{f}}$.

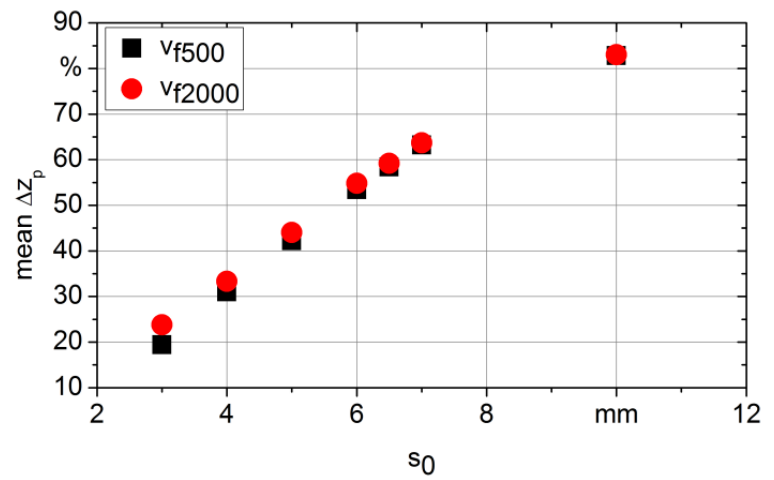

Fig. 6. Mean values of $\Delta z_{p}$ of tubes with different so for vf500 and vf2000.

Figure 7 shows the values of $\Delta y_{p}$ over the radius. In contrast to the axial direction, the material flow in radial direction was not homogeneous with the exception of rods. For tubes, the radial material flow depended on $\mathrm{s}_{0}$. For $\mathrm{s}_{0}$ equaled 3 and $4 \mathrm{~mm}$, the values of $\Delta y_{p}$ were always positive, which means over the whole radius the material was radially stretched. For tubes with higher values of $\mathrm{s}_{0}$, the values of $\Delta \mathrm{y}_{\mathrm{p}}$ changed from positive to negative from inner surface to outer surface. In this case, there was a radial neutral boundary $\left(R_{n}\right)$ that distinguished the radial material flow into local radial compression $\left(\Delta \mathrm{y}_{\mathrm{p}}<0\right)$ and local radial stretching $\left(\Delta y_{p}>0\right)$.

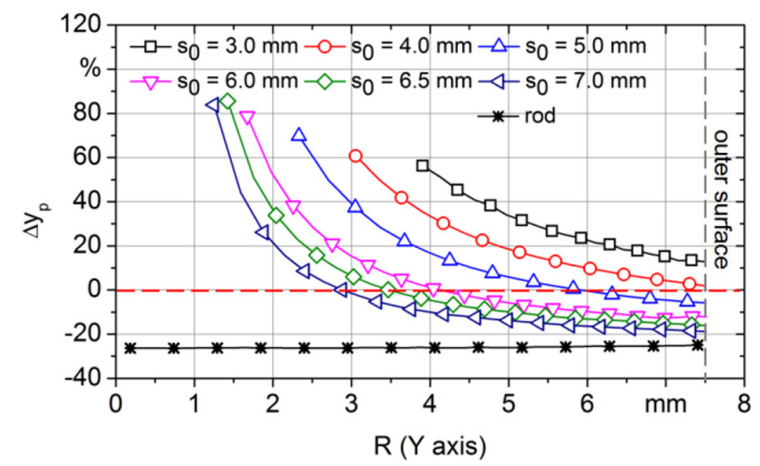

Fig. 7. Radial shape changes $\Delta y_{p}$ along the radius for $v_{f 500}$

The ratios of $R_{n}\left(R_{n p}\right)$ in radial direction (Y axis) for both $\mathrm{v}_{\mathrm{f}}$ with $\mathrm{s}_{0}$ from $5 \mathrm{~mm}$ to $7 \mathrm{~mm}$ were determined and shown in Figure 8. The relative locations of this $R_{n p}$ shifted towards the central axis with bigger $\mathrm{s}_{0}$. Thus in thicker tubes more radial material had the similar behavior to that of rods as expected. For both $\mathrm{v}_{\mathrm{f}}$ the location of $\mathrm{R}_{\mathrm{n}}$ was almost linearly dependent on $\mathrm{s}_{0}$; with the same value of $s_{0}$ the location of $R_{n}$ from higher $v_{f}$ was always nearer to the inner surface. So the effect of increasing $\mathrm{V}_{\mathrm{f}}$ was forcing more material flow to axial direction. The effect of $v_{f}$ in changing radial material flow could help to control the inner profile, for example 
by using two $\mathrm{v}_{\mathrm{f}}$ during the process might create stepped inner structures.

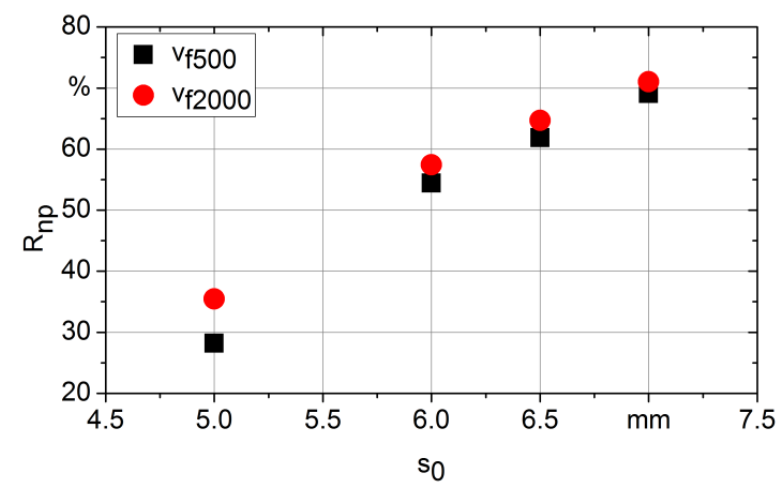

Fig. 8. Ratio of $\mathrm{R}_{\mathrm{np}}$ according to $\mathrm{s} 1$ for both $\mathrm{vf}$ with different $\mathrm{s} 0$

According to former discussion, increasing the wall thickness affected the material flow more than increasing the feeding velocity. Nevertheless, the trend could be derived that the more material to be deformed in one stroke, the harder for material to flow in radial direction. This should be caused by higher resistance against deformation in radial direction or a lower resistance in axial direction. The axial elongation of material could be treated as to be linearly dependent on $\mathrm{s}_{0}$.

For the experimental results, two photographs of tubes ( $\mathrm{s}_{0}$ equals $3 \mathrm{~mm}$ and $7 \mathrm{~mm}$ ) deformed with $\mathrm{v}_{\mathrm{f} 500}$ are shown in Figure 9. The values of $s_{1}$ measured from experiments and FE model are shown in Figure 10, the value of variance of each measurement of experiment is in terms of error bars. In Figure 10 it could be found that the values of simulation is always higher than those of experiment. The over-valuation of $s_{1}$ of FE model could be caused by no-ideal material flow in circumferential direction in 2D-axisymmetric model or by a discrepancy of material property values. Also a simulation in an extended research shown by increasing the friction coefficient from 0.1 to 0.2 the values of $s_{1}$ were reduced, and a former research shown dry rotary swaging of tubes resulted in larger elongation and thinner walls [17]. Hence, the friction coefficient value might be underestimated in the present study. Nevertheless, the maximum value of $\delta$ was $6.7 \%$ for $\mathrm{s}_{0}$ equaled $4 \mathrm{~mm}$ with $\mathrm{V}_{\mathrm{f} 500}$ while the average values were $4.44 \%$ and $3.30 \%$ for $\mathrm{V}_{\mathrm{f} 500}$ and $\mathrm{V}_{\mathrm{f} 2000}$. Thus a good agreement between experiment and FE model was achieved and so the FE model was validated.

To view the changes of wall thickness based on both FE model and experiment, the values of $\Delta s_{p}$ were shown in Figure 11. According to Figure 11 the thickening of the wall (positive values of $\Delta s_{p}$ ) decreased linearly with increasing $\mathrm{s}_{0}$ up to an initial wall thickness of about $\mathrm{s}_{0}=6 \mathrm{~mm}$. Above this threshold the wall thickness decreased by the rotary swaging process $\left(\Delta s_{p}<0\right)$. Also, with a processing parameter dependent value of $\mathrm{s}_{0}$ a not changing wall thickness was observed, which agreed with the simulation results. In addition, it could be verified that higher $\mathrm{v}_{\mathrm{f}}$ led to a lower value of $\mathrm{s}_{1}$, thus increasing $\mathrm{v}_{\mathrm{f}}$ increased the resistance for material flow towards radial direction and forced more material flow towards axial direction. This result agreed with former experimental research of tubes $\left(\mathrm{s}_{0}=2 \mathrm{~mm}\right)$ [17].
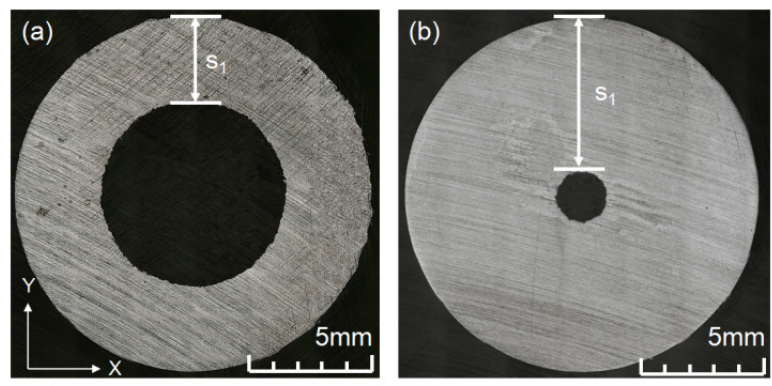

Fig. 9. Cross section of deformed tubes of $\mathrm{vf500}$ (position A-A); (a) $\mathrm{s}_{0}=3 \mathrm{~mm}, \mathrm{~s}_{1}=3.63 \mathrm{~mm}$; (b) $\mathrm{s}_{0}=7 \mathrm{~mm}, \mathrm{~s}_{1}=6.50 \mathrm{~mm}$.

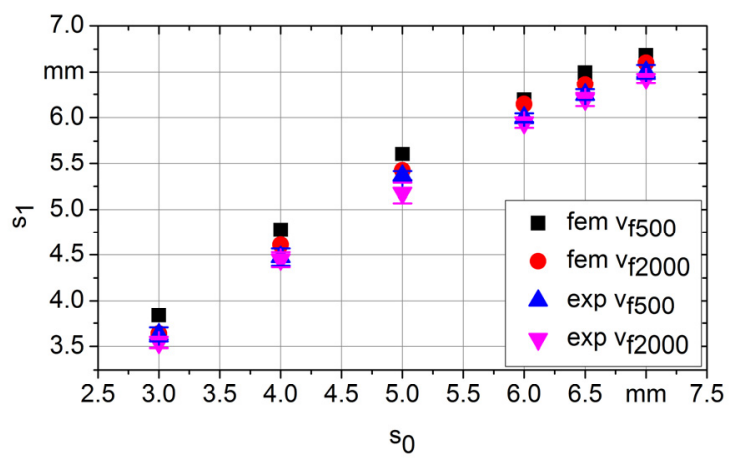

Fig. 10. Comparison of simulations and experiments.

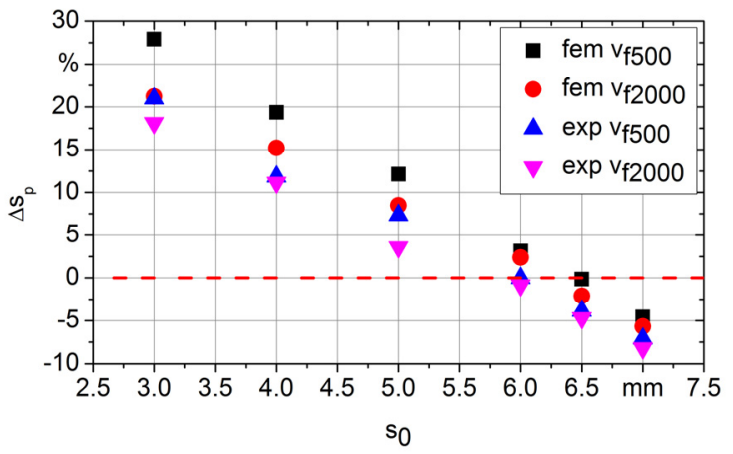

Fig. 11. Relative change of the wall thickness $\Delta \mathrm{s}_{\mathrm{p}}$ at position $\mathrm{A}-\mathrm{A}$ as a function of the initial wall thickness so. Positive values indicate an increase. 


\section{Conclusions and outlooks}

In this paper the axial and radial material flow of steel tubes in mandrel free infeed rotary swaging process were investigated. A 2D-axisymmetric FEM model was built, the shape changes of the deformed meshes were calculated. The experimental validation was carried out by comparing the wall thickness change after the process. Several conclusions could be drawn:

- 2D-axisymetric model is reliable to study the radial and axial material flow in mandrel free tube rotary swaging process;

- axial elongation of the material in mandrel free tube infeed rotary swaging process is homogeneous over the radial position;

- increase of the wall thickness increases the radial material flow more than increasing the feeding velocity;

- the material flow in radial direction near the inner surface of tubes increases with higher initial wall thickness;

- for tubes with a certain wall thickness, there is a radial neutral boundary $\left(R_{n}\right)$ where the material is neither compressed nor stretched, the location of $R_{n}$ is nearer to the outer surface with lower $\mathrm{v}_{\mathrm{f}}$.

Based on the conclusions, the next research should be focused on the validation of radial neutral boundary, and if it affects the mechanical properties that are known to be affected by the actual material flow. Also, more friction conditions should be considered. Other processing parameters like stroke height or frequency are also needed to figure out their influences, which could help to control the material flow. The influence of feeding velocity should be investigated due to the potential to change the wall thickness.

The authors gratefully acknowledge the support by the German Research Foundation for a subproject within the priority program 2013, as well as the support by China Scholarship Council (CSC).

\section{References}

[1] T. Altan, S.-I. Oh, G. Gegel, American Society for Metals 1983, 353 (1983).

[2] S. Ishkina, C. Schenck, B. Kuhfuss, E. Moumi, K. Tobeck, Int. J. Precis. Eng. Manuf 18, 1035 (2017)

[3] S. J. Lim, H. J. Choi, K. H. Na, C. H. Lee, Solid State Phenomena 124. 1645 (2007).

[4] Q. Zhang, K. Jin, D. Mu, P. Ma, J. Tian. Procedia Engineering 81, 2336 (2014).

[5] M. Herrmann, C. Schenck, B. Kuhfuss, Procedia CIRP 40, 654 (2016).
[6] R. Li, Z.-R. Nie, T.Y. Zuo, Transactions of Nonferrous Metals Society of China 16, 1015 (2006).

[7] E. Moumi, S. Ishkina, B. Kuhfuss, T. Hochrainer, A. Struss, M. Hunkel, Procedia Engineering 81, 2342 (2014).

[8] W. Gan, Y. Huang, R. Wang, G. Wang, A. Srinivasan, H.-G. Brokmeier, N. Schell, K. Kainer, N. Hort, MATER DESIGN 63, 83 (2014).

[9] M. A. Abdulstaar, E. A. El-Danaf, N. S. Waluyo, L. Wagner, Mater. Sci. Eng., A 565, 351 (2013).

[10] S. Ishkina, B. Kuhfuss, C. Schenck. Key Engineering Materials 651, 627 (2015).

[11] Y. Li, J. Huang, G. Huang, W. Wang, J. Chen, Z. Zeng. MATER DESIGN 56, 822 (2014).

[12] Y. Liu, M. Herrmann, C. Schenck, B. Kuhfuss, AIP Conference Proceedings 1896 (2017).

[13] X. Tan, Tribology International 35, 385 (2002).

[14] E. Q. Sun, In MSC Software Corporation's 2006 Americas Virtual Product Development Conference: Evolution to Enterprise Simulation, 17 (2006)

[15] E. Doege, H. Meyer-Nolkemper, I. Saeed, Fließkurvenatlas metallischer Werkstoffe, Hanser Verlag, Wien (1986).

[16] H. Czichos, K.-H. Habig, J.-P. Celis, TribologieHandbuch: Tribometrie, Tribomaterialien, Tribotechnik, Vieweg + Teubner, Wiesbaden (2010).

[17] M. Herrmann, B. Kuhfuss, C. Schenck, Key Engineering Materials 651, 1042 (2015). 